\title{
Valuing wetlands
}

\author{
Wetlands provide a wealth of societal and climatic benefits. Balanced conservation strategies are needed to ensure \\ their protection in the twenty-first century and beyond.
}

T he monetary value of ecosystem services provided by wetlands globally is estimated to be some Int $\$ 47$ trillion per year ${ }^{1}$. Of course, this only captures the subset of benefits that are quantifiable economically, and probably fails to capture the much broader value wetlands have for millions of people in terms of cultural heritage and water security. Despite this, these ecosystems are highly threatened by human development. With the theme of World Water Day this year being 'Valuing water', here we reflect on the current state of these diverse, essential ecosystems.

Benefits often come from the interconnectedness of these water systems, which can span mangroves and estuaries along the coast to marshes, lakes and rivers inland. They act as multi-layered flood-protection systems by regulating river drainage and groundwater flow, and help stabilize coastlines. They filter water on an enormous scale, for instance by removing nitrates from agricultural run-off that contribute to algal blooms, drinking-water degradation and hypoxia ${ }^{2}$. Crucially, they also store vast quantities of carbon in their organic matter-rich sediments, representing the largest sink among all terrestrial ecosystems. These are just some examples. According to a recent report ${ }^{3}$, wetlands contribute to 75 United Nations Sustainable Development Goal indicators.

The complex web of interacting processes in wetlands may extend well beyond any single site. This also makes decisions on how best to protect them highly challenging. Fifty years ago saw the signing of the Ramsar Convention on Wetlands, an intergovernmental treaty enacted for their conservation and sustainable use. Since then, more than 2,300 sites have been designated to be of international importance across more than 170 signatory countries. Nevertheless, $35 \%$ of the area covered by wetlands when the treaty came in to force has been lost since then, with particularly rapid declines among inland wetlands - a trend driven mostly by drainage for conversion to agricultural, residential and industrial land uses. In stark contrast, artificial wetlands have increased.

After half a century of protection efforts, this rate of wetland loss is alarming. Lack of effective governance at many sites is undoubtedly a major driver, and Ramsar itself has been criticized for not having sufficiently strong mechanisms in place to hold signatories to account for degradation of listed sites ${ }^{4}$. Only recently, the whole of the Ramsar-listed Matogrossense National Park in Brazil was burned, along with large swathes of the Patanal wetlands in which it is located - an unprecedented event that some have attributed to weakening of laws governing land use and agriculture ${ }^{5}$. Similarly, licenses have recently been granted in Namibia and Botswana for oil and gas exploration upstream of the Okavango Delta, posing a risk of groundwater contamination in one of the world's iconic wetlands. Within the past few years, the US government has rolled back protections of vulnerable waters under the Clean Water Rule, specifically targeting intermittent, seasonally flowing waters that make up some $16 \%$ of wetland area in the United States, which remain poorly protected from deregulation ${ }^{6}$.

Innovative legal strategies have recently provided reason for hope. In 2017, local Māori tribes in New Zealand successfully campaigned for the Whanganui River to be granted the same legal rights as people, with similar cases being successfully fought for the Yamuna and Ganges rivers in India. The latter of these represent some the most polluted water courses in the world. It remains to be seen how effective new legal frameworks will be in ensuring that action is taken to clean them up.

If protection is not enough, what are the alternatives? This year also marks the start of the United Nations Decade on Ecosystem Restoration, and as with other threatened or declining habitats, there is potential to mobilize support for large-scale wetland restoration projects. Recent analysis of wetlands in the United States suggest that there is huge potential for gains in terms of nitrate removal and water-quality improvements from targeted, modest investments in expanding wetlands ${ }^{7}$. Similarly, wetland expansion and conservation aimed at locking carbon in wetland sediments can potentially be used as a climate change mitigation strategy.
This work, however, needs to be based on a careful consideration of whether protection or restoration should be prioritized ${ }^{8}$.

Wetlands can act as both carbon sources and sinks depending on local environmental conditions, and restoration schemes may be more cost-effective for coastal than inland systems ${ }^{9}$. Where large-scale restoration initiatives already exist, they rarely outpace rates of loss. For example, the extent of wetland destruction in China in the twenty-first century alone has been more than twice that of gains from conservation efforts ${ }^{10}$.

Wetlands are variable, complex systems. For restoration projects to succeed, we must first better understand the characteristics of sites that make them amenable to restoration, and the timescales over which we might expect restoration to provide tangible benefits. In the face of rapid climate change, we also need to better understand their resilience to novel conditions, hazards and degradation ${ }^{11}$.

Decisions about whether to restore or protect must be grounded in sound science, and supported by local people who rely on the services wetlands provide, to ensure that shared values and trust are embedded in the decision-making process. Until then, ensuring that legal protections are robust to the many and varied threats wetlands face should remain a priority.

Published online: 8 March 2021 https://doi.org/10.1038/s41561-021-00713-4

References

1. Davidson, N. C., van Dam, A. A., Finlayson, C. M. \& McInnes, R. J. Mar. Freshw. Res. 70, 1189-1194 (2019).

2. Hansen, A. T., Dolph, C. L., Foufoula-Georgiou, E. \& Finlay, J. C. Nat. Geosci. 11, 127-132 (2018).

3. Global Wetland Outlook: State of the World's Wetlands and Their Services to People 2018 (Ramsar Convention, 2018).

4. Bridgewater, P. \& Kim, R. E. Nat. Ecol. Evol. https://doi. org/10.1038/s41559-021-01392-5 (2021).

5. Libonati, R., DaCamara, C. C., Peres, L. F., Sander de Carvalho, L. A. \& Garcia, L. C. Nature 588, 217-219 (2020)

6. Creed, I. F. et al. Nat. Geosci. 10, 809-815 (2017).

7. Cheng, F. Y., Van Meter, K. J., Byrnes, D. K. \& Basu, N. B. Nature 588, 625-630 (2020).

8. Griscom, B. W. et al. Proc. Natl Acad. Sci. USA 114, 11645-11650 (2017).

9. Taillardat, P., Thompson, B. S., Garneau, M., Trottier, K. \& Friess, D. A. Interface Focus 10, 20190129 (2020).

10. Xu, W. et al. Curr. Biol. 29, 3065-3071 (2019).

11. Xi, Y., Peng, S., Ciais, P. \& Chen, Y. Nat. Clim. Change 11 45-51 (2021). 